Proc. Indian Acad. Sci. (Chem. Sc1.), Vol. 98, No. O. Maicn 198, pp. 161-164. (C) Printed in India

\title{
Lanthanide perchlorate complexes of 2-acetamidopyridine-1-oxide
}

\author{
N S NAVANEETHAM, R KALYANASUNDARAM, N RAJASE- \\ KAR* $^{*}$ and S SOUNDARARAJAN \\ Department of Inorganic and Physical Chemistry, Indian Institute of Science, Bangalore \\ 560012 , India \\ MS received 8 September 1986; revised 4 December 1986

\begin{abstract}
AcAmPyO) complexes of six lanthanide perchlorates, with the general composition $\mathrm{Ln}(\mathrm{AcAmPyO})_{5}\left(\mathrm{ClO}_{4}\right)_{3}$, have been synthesized and characterized by analysis, molar conductance, infrared, proton NMR and electronic spectral data. Infrared and conductance studies indicate the ionic nature of the anion. The coordination of the ligand through the $\mathrm{N}-\mathrm{O}$ and $\mathrm{C}=\mathrm{O}$ moieties is shown by the infrared and proton NMR spectral analysis.
\end{abstract}

Keywords. Lanthanide perchlorate complexes; 2 -acetamidopyridine-1-oxide; IR spectra; proton NMR; electronic spectra.

\section{Introduction}

A survey of the literature in the field of lanthanide coordination chemistry reveals that although lanthanide complexes with neutral bidentate pyridine-1-oxide ligands like picolinamide-1-oxide (Navaneetham and Soundararajan 1979) are known, pyridine-1-oxide ligands containing the $-\mathrm{NHCOCH}_{3}$ (acetamido) group have not been employed for complexation with lanthanides. We report in this paper the synthesis and characterization of new perchlorate complexes of six lanthanides with 2-acetamidopyridine-1-oxide (AcAmPyO).

\section{Experimental}

\subsection{Materials}

2-aminopyridine was obtained from Aldrich Chemical Company, USA and used as such. Hydrated lanthanide perchlorates were obtained as reported earlier (Behrendt and Madan 1976).

\subsection{Synthesis of AcAmPyO}

2-aminopyridine $(0.1 \mathrm{~mol})$ was refluxed with freshly distilled acetic anhydride $(0.11$ mol) for two hours. Acetic acid and acetic anhydride were removed by distillation at $100 \mathrm{~mm} / \mathrm{Hg}$ pressure. The solid residue was recrystallized from ether to get colourless plates of 2 -acetamido pyridine (m.p. $66^{\circ} \mathrm{C}$; Lit. $66-7^{\circ} \mathrm{C}$ ). The acetamidopyridine was then $\mathrm{N}$-oxidised adopting the method described by Ochidi (1967)

\footnotetext{
* To whom all correspondence should be addressed.
} 
for the preparation of quinoline-1-oxide. The crude product was recrystallized from acetone m.p. $132^{\circ} \mathrm{C}$ (Lit. $131-32^{\circ} \mathrm{C}$ ).

\subsection{Preparation of the complexes}

To a hot solution of AcAmPyO (12 mmol) in ethylacetate $(50 \mathrm{ml})$, a solution of hydrated lanthanide perchlorate $(1 \mathrm{mmol})$ also taken in ethylacetate $(5 \mathrm{ml})$ was added with stirring. Stirring in the hot condition was continued for 10 minutes. The solvent was then decanted and the sticky mass thus obtained was washed thrice with hot chloroform $(10 \mathrm{ml})$ to remove any unreacted ligand, washed twice with dry diethyl ether $(15 \mathrm{ml})$, and finally dried in vacuo $(\approx 3 \mathrm{~mm} / \mathrm{Hg})$ at $80-85^{\circ} \mathrm{C}$ for about 30 minutes to get the dry solid complex.

\subsection{Analyses}

The metal and anion contents in all the complexes were estimated as reported previously (Serra et al 1976); ligand was estimated spectrophotometrically at $230 \mathrm{~nm}$ using the calibration curve method.

\subsection{Physical measurements}

Conductance measurements in acetonitrile, infrared spectra in mulls, proton NMR spectra of the ligand and its $\mathrm{La}^{3+}$ complex in $\mathrm{CD}_{3} \mathrm{CN}$ and electronic spectra both in solution (acetonitrile) and solid state (mulls) were obtained by the methods described previously elsewhere (Rajasekar and Soundararajan 1981).

\section{Results and discussion}

Analytical data for the newly prepared complexes listed in table 1 indicate that five molecules of the ligand are associated with each tripositive lanthanide ion $\mathrm{Ln}(\mathrm{AcAmPyO})_{5}\left(\mathrm{ClO}_{4}\right)_{3}$. Molar conductance values in acetonitrile indicate that all the six complexes behave as 1:3 electrolytes (Geary 1971). The complexes are hygroscopic and soluble in polar solvents such a methanol, acetone, acetonitrile, DMSO and DMF but insoluble in $\mathrm{CCl}_{4}$, chloroform and benzene.

Table 1. Analytical and molar conductance data for the AcAmPyO complexes of lanthanides.

\begin{tabular}{|c|c|c|c|c|c|c|c|}
\hline \multirow{2}{*}{ Complex } & \multicolumn{2}{|c|}{ Metal (\%) } & \multicolumn{2}{|c|}{ Ligand $(\%)$} & \multicolumn{2}{|c|}{$\mathrm{ClO}_{4}^{-}(\%)$} & \multirow{2}{*}{$\Lambda_{M}^{+}$} \\
\hline & Found & Calcd. & Found & Calcd. & Found & Calcd. & \\
\hline $\mathrm{La}(\mathrm{AcAmPyO})_{s}\left(\mathrm{ClO}_{4}\right)_{3}$ & $14 \cdot 48$ & $11 \cdot 60$ & $62 \cdot 53$ & 63.48 & $24 \cdot 80$ & 24.92 & $389 \cdot 2$ \\
\hline $\operatorname{Md}(\operatorname{AcAmPyO})_{1}\left(\mathrm{ClO}_{4}\right)_{3}$ & 11.87 & 11.99 & $62 \cdot 56$ & $63 \cdot 19$ & - & - & 363.8 \\
\hline $\mathrm{Gd}(\mathrm{AcAmPyO})_{5}\left(\mathrm{ClO}_{4}\right)_{3}$ & $12 \cdot 80$ & $12 \cdot 94$ & $61 \cdot 89$ & 62.52 & - & - & $350 \cdot 2$ \\
\hline $\operatorname{Dy}(\operatorname{AcAmPyO})_{5}\left(\mathrm{ClO}_{4}\right)_{3}$ & $13 \cdot 18$ & $13 \cdot 31$ & 61.75 & $62 \cdot 25$ & $24 \cdot 38$ & $24 \cdot 44$ & $\mathbf{3 4 2} \cdot 3$ \\
\hline $\mathrm{Ho}(\mathrm{AcAmPyO})_{5}\left(\mathrm{ClO}_{4}\right)_{3}$ & $13 \cdot 36$ & 13.48 & $61 \cdot 52$ & $62 \cdot 13$ & - & - & $348 \cdot 8$ \\
\hline $\mathrm{Yb}(\mathrm{AcAmPyO})_{5}\left(\mathrm{ClO}_{4}\right)_{3}$ & 13.93 & 14.05 & $61 \cdot 10$ & $61 \cdot 72$ & - & - & $349 \cdot 8$ \\
\hline
\end{tabular}

+ Molar conductance in acetonitrile $\left(\mathrm{Ohm}^{-1} \mathrm{~cm}^{2} \mathrm{~mol}^{-1}\right)$. 


\subsection{IR spectra}

The presence of a very strong band in the region $1085-1105 \mathrm{~cm}^{-1}\left(\nu_{3}\right)$ and a medium unsplit one in the region $620-622 \mathrm{~cm}^{-1}\left(\nu_{4}\right)$ in the IR spectra of all the complexes (table 2) confirms evidence of non-coordinated perchlorates from conductivity measurements. Coordination of the perchlorate groups would result in a lowering of the symmetry from $T_{d}$ symmetry and a splitting of these bands.

The shifts in $\nu_{\mathrm{N}-\mathrm{O}}$, amide I and amide II, $\delta_{\mathrm{N}-\mathrm{O}}$ and the $\gamma_{\mathrm{C}-\mathrm{H}}$ bands of the ligand in the complexes indicate the coordination of the $\mathrm{N}$-oxide and $\mathrm{C}=\mathrm{O}$ groups of the ligand to the tripositive lanthanide ion. The $\nu_{\mathrm{N}-\mathrm{O}}$ and the amide $\mathrm{I}$ bands are lowered by $5 \mathrm{~cm}^{-1}$, while the amide II, $\delta_{\mathrm{N}-\mathrm{O}}$ and $\gamma_{\mathrm{C}-\mathrm{H}}$ bands are shifted to higher frequencies by 5,10 and $15 \mathrm{~cm}^{-1}$, respectively, in the complexes. These positive shifts amply demonstrate a decrease in the $\pi$-electron density of the amide groups and the heterocyclic ring as a result of the bidentate binding of the ligand, through the $\mathrm{N}$-oxide and amide carbonyl groups, to the lanthanide ion.

\subsection{Proton NMR spectra}

Additional evidence for the coordination of the ligand is provided by the proton NMR spectra of the ligand and $\mathrm{La}^{3+}$ complex (diamagnetic). The spectral data are given in table 3 . The downfield shifts of all the ring proton signals observed in the $\mathrm{La}^{3+}$ complex (compared to the ligand) concomitantly prove the coordination of the ligand to the metal ion via the $\mathrm{N}-\mathrm{O}$ and $\mathrm{C}=\mathrm{O}$ groups.

\subsection{Electronic spectra}

The electronic spectral assignments of $\mathrm{Nd}^{3+}$ and $\mathrm{Ho}^{3+}$ complexes along with their $J$-level assignments are presented in table 4.

Tabłe 2. Important infrared frequencies (in $\mathrm{cm}^{-1}$ ) and their assignments for AcAmPyO and its complexes.

\begin{tabular}{lccccccc}
\hline Ligand & La & Nd & Gd & Dy & Ho & Yb & Assignment \\
\hline $3175-$ & $3325-$ & $3300-$ & $3300-$ & $3325-$ & $3325-$ & $3325-$ & $\nu_{\text {NH }}$ \\
$3400 w b$ & $3425 w b$ & $3400 w b$ & $3400 w b$ & $3425 w b$ & $3425 w b$ & $3425 w b$ & \\
$1710 s$ & $1705 m$ & $1702 m$ & $1702 m$ & $1705 m$ & $1708 m$ & $1705 m$ & Amide I \\
$1575 m$ & $1580 m$ & $1580 m$ & $1582 m$ & $1580 m$ & $1585 m$ & $1580 w$ & Amide II \\
$1278 m$ & $1270 w$ & $1270 w$ & $1270 w$ & $1270 w$ & $1270 w$ & $1275 w$ & $\nu_{\text {N }-O}$ \\
- & $1090 s$ & $1090 s$ & $1090 s$ & $1090 s$ & $1105 s$ & $1085 s$ & $\nu_{3 C 1 O 4}$ \\
$860 w$ & $870 w$ & $870 w$ & $870 w$ & $870 w$ & $865 w$ & $865 w$ & $\delta_{N-O}$ \\
$745 w$ & $755 w$ & $755 w$ & $758 w$ & $755 w$ & $760 w$ & $758 w$ & $\gamma_{C-11}$ \\
- & $620 m$ & $620 m$ & $620 m$ & $622 m$ & $621 m$ & $620 m$ & $\nu_{d C I O 4}$ \\
\hline
\end{tabular}

Abbreviations: $w=$ weak; $s=$ strong; $m=$ medium; $b=$ broad.

Table 3. Proton NMR spectral data for AcAmPyO and its $\mathrm{La}^{3+}$ complex in $\mathrm{CD}_{3} \mathrm{CN}$ (chemical shifts in $\delta$ w.r.t. TMS).

\begin{tabular}{lllll}
\hline Compound & $3 \mathrm{H}$ & $4 \mathrm{H}$ & $5 \mathrm{H}$ & $6 \mathrm{H}$ \\
\hline AcAmPyO & 6.97 & $7 \cdot 22$ & 6.69 & $8 \cdot 18$ \\
$\mathrm{La}^{3+}$ complex & $7 \cdot 03$ & $7 \cdot 34$ & $6 \cdot 71$ & 8.27 \\
\hline
\end{tabular}


Table 4. Electronic spectral data for AcAmPyO complexes of $\mathrm{Nd}^{3+}$ and $\mathrm{Ho}^{3+}$

\begin{tabular}{|c|c|c|c|}
\hline \multicolumn{2}{|c|}{$\mathrm{Nd}^{3+}$} & \multicolumn{2}{|c|}{$\mathrm{Ho}^{3+}$} \\
\hline$J$ level & Energy $(K K)$ & $J$ level & Energy $(\mathrm{KK})$ \\
\hline $\begin{array}{r}{ }^{4} G_{7 / 2}, \\
{ }^{4} G_{5 / 2}{ }^{2} G_{7 / 2} \\
\beta= \\
\delta= \\
\delta=\end{array}$ & $\begin{array}{r}19.05 \\
17 \cdot 13 \\
0.9942 \\
0 \cdot 5870\end{array}$ & $\begin{array}{c}{ }^{5} F_{1}{ }^{5} G_{6} \\
{ }^{5} F_{3} \\
{ }^{\beta} \\
\quad \\
\quad \delta= \\
\delta=\end{array}$ & $\begin{array}{r}22 \cdot 15 \\
20 \cdot 31 \\
0 \cdot 9928 \\
0 \cdot 7239\end{array}$ \\
\hline
\end{tabular}

The various bands exhibit red shifts with respect to the aquo ion and the nephelauxetic shifts are in the range found for many lanthanide complexes. Sinha (1966) has proposed a $\delta$ scale to express and metal-ligand covalency, which is given by the relation

$$
\delta(\text { percent })=[(1-\beta) / \beta] \times 100,
$$

whare $\beta$ is the average value of $\nu_{\text {complex }} / \nu_{\text {aquo }}$. The positive values of $\delta$ suggest a certain amount of covalency in the metal-ligand band in the six lanthanide complexes. The shapes of the hypersensitive bands resemble those of the ten coordinate lanthanide nitrate complexes of 2-N-acetylaminopyridine (Rajasekar 1980). The marked similarities in the positions and the shapes of the bands in the solid state and in solution point to similarities in the coordination environment around the lanthanide ions in both the states and, hence, the compatibility in the solid state properties such as infrared and solution properties as well as conductivity and proton NMR.

On the basis of these available pieces of evidence a tentative coordination number of ten can be suggested for all the six lanthanide perchlorate complexes of AcAmPyO.

\section{Acknowledgements}

The authors are thankful to the Sophisticated Instruments Facility for the proton NMR spectra. RK thanks the UGC, New Delhi, for a fellowship.

\section{References}

Behrendt J R and Madan S K 1976 J. Inorg. Nucl. Chem. 381827

Geary W J 1971 Coord. Chem. Rev. 781

Navaneetham N S and Soundararajan S 1979 lnorg. Nucl. Chem. Lett. 15379

Ochidi E 1967 Aromatic Amine Oxides (Amsterdam: Elsevier) p. 24

Rajasekar N 1980 Studies in lanthanide chemistry Ph. D. thesis, Indian Institute of Science, Bangalore Rajasekar N and Soundararajan S 1981 J. Inorg. Nucl. Chem. 43977

Strra O A, Perrier M, Lakatas Osorio V K and Kawano Y 1976 Inorg. Chim. Acta 17135 Sinha S P 1966 Spectrochim. Acta 2257 